\title{
Arranjos Cognitivos: Abrangências e Limitações Representacionais ${ }^{1}$
}

\author{
Patrick Wagner de Azevedo \\ Sylvia Beatriz Joffily ${ }^{2}$ \\ Universidade Estadual do Norte Fluminense Darcy Ribeiro (UENF)
}

\begin{abstract}
RESUMO - Este artigo avalia as características quantitativas (dimensões dos campos sensoriais) e qualitativas (padrões configuracionais, qualias e tempo/espaciais) das modalidades sensoriais faltantes e remanescentes e como elas afetam o arranjo cognitivo e a fluência representacional de indivíduos sensorialmente privados (cegos e surdos). Sugere-se que a utilização precoce e maciça do caráter predominantemente configuracional da modalidade sensorial visual, principal modalidade remanescente nos surdos congênitos, iniba a produção representacional nesses indivíduos, enquanto que o uso intensivo e precoce do caráter predominantemente insinuador da modalidade sensorial auditiva, principal modalidade nos cegos congênitos, incentive a produção representacional nesses últimos.
\end{abstract}

Palavas-chave: arranjos cognitivos; privação sensorial; modalidade sensorial remanescente; modalidade sensorial faltante; representação mental.

\section{Cognitive Arrangements: Scope and Representational Limitations}

\begin{abstract}
This study evaluates the quantitative (sensorial field's dimensions) and qualitative (configuration's patterns, qualias and spatial/time) characteristics of missing and remaining sensorial modalities and how they affect the cognitive arrangement and the representational fluency of sensorial impaired individuals (blindness and deafness). It is suggested that precocious and massive use of the predominantly configurational nature of the visual sensorial modality, the main modality remaining on born deaf subjects, inhibit their representational production, while the intensive and precocious use of the predominantly insinuating nature of the auditive sensorial modality, the main modality on born blind subjects, encourages representational production on them.
\end{abstract}

Key words: cognitive arrangements; sensorial privation; remaining sensorial modality; missing sensorial modality; mental representation.

Embora os arranjos cognitivos, que dão origem à riqueza e à diversidade das habilidades mentais e físicas dos homens, tenham sido objetos de muitas pesquisas teóricas e experimentais, poucas são as que se dedicaram a avaliar o poder modelador de suas características (qualitativas e quantitativas) modais sensoriais. Porém, no momento em que se reconhece em cada modalidade sensorial: diferentes momentos de implantação e maturação; campos sensoriais com diferentes amplitudes; órgãos sensoriais periféricos com vários graus de sensibilidade, mobilidade e intencionalidade; diferentes maneiras de captar, reter, configurar e analisar os estímulos; possibilidade de retroceder ou não à experiência sensorial pretérita; capacidade de insinuar ou de configurar estímulos; diferentes qualia e outras características não menos importantes, a relevância metodológica da análise comparativa entre os arranjos cognitivos do indivíduo vidente-ouvinte, cego-ouvinte e surdo-vidente, torna-se clara. Para um melhor entendimento dessa análise comparativa propõem-se alguns princípios:

1 Os autores agradecem aos membros do Núcleo de Estudos e Pesquisas em Neuropsicologia Cognitiva pelo apoio técnico e pelas férteis discussões.

2 Endereço para correspondência: Laboratório de Cognição e Linguagem - LCL. Centro de Ciências do Homem - CCH. Universidade Estadual do Norte Fluminense Darcy Ribeiro - UENF. Ave. Alberto Lamêgo 2000, Parque Califórnia, Campos dos Goytacazes. Rio de Janeiro, RJ. CEP 28013-602.E-mail: joffily.uenf@gmail.com.
1) cada modalidade sensorial possui características quantitativas e qualitativas que lhe são próprias;

2) a eficácia funcional dessas características é passível de ser avaliada por meio de critérios quantitativos e qualitativos;

3) a eficácia e o aprimoramento funcional das modalidades sensoriais dependem da associação que cada modalidade sensorial estabelece com as demais modalidades e com o sistema motor, mais especificamente com o grau de mobilidade alcançada pelos seus órgãos sensoriais periféricos;

4) o valor funcional de cada modalidade sensorial só pode ser verdadeiramente avaliado dentro de contextos intermodais sensoriais e motor;

5) o arranjo cognitivo dos indivíduos que, por diferentes razões, encontram-se privados de uma ou mais modalidades sensoriais é determinado, não só pela inoperância das características quantitativas e qualitativas da modalidade faltante, mas, sobretudo, pela eficácia do arranjo gerado pelo conjunto das características qualitativas e quantitativas modais sensoriais remanescentes;

6) a eficácia funcional das modalidades remanescentes componentes dos novos arranjos cognitivos depende do momento em que a perda da modalidade sensorial faltante acontece;

7) o sucesso da reabilitação cognitiva de indivíduos sensorialmente privados (surdos e cegos) depende do grau de conhecimento que o próprio, os profissio- 
nais e os familiares envolvidos no processo possuam acerca das características quantitativas e qualitativas das diferentes modalidades sensoriais.

Considerando que o arranjo cognitivo dos indivíduos sensorialmente privados se altera no momento em que as modalidades sensoriais remanescentes são sobrecarregadas pelas funções da modalidade sensorial faltante, propõe-se, neste artigo, não só analisar as características originais, quantitativas e qualitativas, da modalidade sensorial faltante, como também as características originais e adquiridas, quantitativas e qualitativas, das modalidades sensoriais remanescentes funcionalmente predominantes. Sendo assim, para melhor se compreender o arranjo cognitivo dos indivíduos cegos, faz-se necessário estudar não só as características quantitativas e qualitativas da visão, como também as características quantitativas e qualitativas da audição e da modalidade tátil/háptica. Similarmente, para melhor se compreender o arranjo cognitivo dos indivíduos surdos, faz-se necessário estudar não só as características quantitativas e qualitativas da audição, como também as características quantitativas e qualitativas da visão e da modalidade tátil/háptica.

A partir dessas considerações, ousa-se perguntar: seria viável, baseando-se em características modais sensoriais, estabelecer um estudo teórico comparativo entre a eficácia cognitiva do arranjo sensorial dos cegos congênitos, que têm como atividade sensorial remanescente as modalidades auditiva e tátil/háptica, e a eficácia cognitiva do arranjo sensorial dos surdos congênitos, que têm como atividade sensorial remanescente as modalidades visual e tátil/háptica? Reforçando o caráter inaugural, teórico e reflexivo da presente proposta, analisa-se, a seguir, algumas das características modais sensoriais que estão no cerne dessa questão.

\section{As Modalidades Sensoriais no Desenvolvimento Cognitivo dos Homens}

Segundo Radeau (1997), a implantação das modalidades sensoriais segue uma cronologia bem definida ao longo do desenvolvimento cognitivo dos homens. Em primeiro lugar, instala-se a modalidade tátil; em segundo, a vestibular (manutenção do equilíbrio e orientação espacial); em terceiro, as químicas (gustação e olfação); em quarto, a auditiva; e, por último, a visual. Porém, o mesmo autor adverte, sempre que essa cronologia geneticamente pré-determinada é por um motivo ou por outro alterada, todo o sistema cognitivo se modifica originando um novo arranjo cognitivo.

Essa cronologia, que para Proust (1997) teria a finalidade de não só preservar o organismo ainda imaturo do excesso de estimulação externa, como também reduzir toda e qualquer possibilidade de rivalidade sensorial intermodal, merece maior atenção. A análise conjunta das características "implantação" e "maturação" revela-se fundamental, sobretudo, no caso das modalidades cujos órgãos sensoriais periféricos ou parte deles apresente mobilidade significativa como os olhos, no caso da visão, e as mãos, no caso da modalidade háptica. A relevância dessa análise fica mais clara quando se avalia o desempenho das modalidades visual e somato-motora no planejamento mental de ações em primeira e terceira pessoas. Segundo Imbiriba,
Tabela 1. Características de implantação x maturação das modalidades sensoriais.

\begin{tabular}{|c|c|c|c|}
\hline & \multicolumn{2}{|c|}{ Sistemas Sensoriais de Implantação } \\
\hline & & Precoce & Tardia \\
\hline 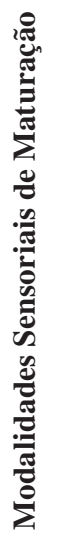 & 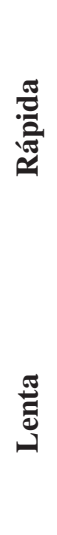 & $\begin{array}{c}\text { Háptico (versão mouthing) } \\
\text { Olfato } \\
\text { Gustação } \\
\\
\text { Tato passivo } \\
\text { Equilíbrio } \\
\text { Audição }\end{array}$ & $\begin{array}{c}\text { Visão } \\
\text { Háptico (versão manual) }\end{array}$ \\
\hline
\end{tabular}

Rodrigues, Magalhães e Vargas (2006) e Imbiriba e cols. (2008), as estratégias modais sensoriais utilizadas nessas ações por indivíduos videntes e por cegos tardios diferem das utilizadas pelos indivíduos cegos congênitos. Na Tabela 1 pode-se visualizar de forma esquematizada a cronologia da implantação e da maturação das diferentes modalidades sensoriais.

A ideia de ser o tato uma modalidade sensorial primordial, reflexa e passiva, cuja versão ativa e intencional (háptica) só acontece no momento em que as áreas associativas corticais cerebrais amadurecem, permitindo que a informação sensorial se alie à destreza motriz, não se sustenta frente aos novos achados da neuropsicologia cognitiva. Pesquisas evidenciam que além das mãos, outras áreas do corpo humano estão, desde as fases mais precoces do desenvolvimento, dotadas com as características que distinguem o tato passivo reflexo do tato ativo, intencional ou háptico.

Com os achados de Bullinger e Rochat (1985, apud Hatwell, Streri \& Gentaz, 2000), a sucção, considerada durante muito tempo uma atividade precoce, fisiológica, invariável e rígida, conquista a condição de função cognitiva háptica. Por meio de gráficos, Bullinger e Rochat demonstraram que o traçado regular da sucção precoce não nutritiva podia ser temporariamente substituído por outro, irregular, de fraca amplitude, relacionado às deformações mecânicas da boca e da língua, as quais se assemelhavam às das mãos em apalpação. Em outro experimento, no qual foram apresentadas a bebês de quatro meses de idade uma série de chupetas com formas e características físicas variáveis (rígidas e flexíveis), Rochat (1983) constatou que enquanto o primitivo padrão da sucção regular diminuía com a idade, o padrão da sucção não regular, exploratória, aumentava. Além disso, ele também observou que o interesse dos bebês pelas características modais sensoriais das chupetas variava de acordo com a idade. Enquanto que os bebês mais jovens respondiam, sobretudo, às suas características físicas (rigidez e flexibilidade), os mais velhos reagiam aos seus formatos. Ruff, Saltarelli, Capozzoli e Dubiner (1992) observaram que a exploração háptica oral ou mouthing, que predomina nos bebês até os sete meses de vida pós-natal, começa a declinar no momento em que a atividade háptica manual tem início. Esses achados encontram 
respaldo, dentre outros, nos trabalhos dedicados ao conceito de intermodalidade (Gibson \& Walker, 1984; Gottfried, Rose \& Bridger, 1977; Meltzoff \& Borton, 1979; Pêcheux, Lepecq \& Salzarulo, 1988). A partir do momento em que a boca e a língua são reconhecidas como órgãos dotados de atividade háptica, as características qualitativas temporais e espaciais que definem as diferentes formas de captação de estímulos (simultânea $\mathrm{x}$ sequencial e distal x proximal, respectivamente) também são questionadas e o conceito de intermodalidade, explicitado ainda de forma incipiente na tradicional pergunta de Molineux: "Um cego de nascença, poderia ou não, tendo recobrado a visão, distinguir visualmente um cubo de uma esfera sem tê-las tocado previamente?" (citado por Proust, 1997, p. 162), ganha surpreendentes desdobramentos teóricos e práticos.

Na década de 70 do século passado, Bach-y-Rita (1972) desenvolveu um dispositivo de substituição sensorial (tactile vision substitution system, TVSS) que permitia que cegos congênitos experimentassem, por meio do tato, modalidade considerada até então "proximal" e "sequencial", a "simultaneidade distal" cognitiva que se acreditava ser privilégio da visão. Posteriormente, Bach-y-Rita e Sampaio (1995) e Segond, Weiss e Sampaio (2007) pesquisaram esse dispositivo com bebês cegos. Além da sua enorme relevância prática, o dispositivo de Bach-y-Rita teve o mérito de evidenciar que o reconhecimento de um espaço distal, estável, externo e independente resultava, sobretudo, da associação da modalidade sensorial visual e tátil à motricidade intencional ou voluntária. Os movimentos da face (olhos, boca e língua), do tronco e dos membros, executados pelos fetos e recém-nascidos durante o seu estado de "sono agitado", seriam, segundo Adrien (1977), Joffily (1995, 2004) e Jouvet (1998), fundamentais para a instalação da futura experiência sensorial distal. Já a imobilidade dos ouvidos humanos não favorece a mesma associação sensório-motora no âmbito da audição. Entretanto, as diferenças semânticas existentes entre os verbos ver e olhar, no caso da visão, e ouvir e escutar, no caso da audição, denunciam o estabelecimento de um outro tipo de associação entre as modalidades sensoriais e a função atencional. Em um estudo com cegos tardios, Kastrup (2007) destaca a atenção como elemento organizador das modalidades sensoriais componentes do seu arranjo cognitivo remanescente.

$\mathrm{Na}$ Tabela 2 encontram-se esquematizadas as relações que as características temporais (sequenciais e simultâneas) estabelecem com as características espaciais (distais e proximais) das diferentes modalidades sensoriais.

\section{O Espaço e as Características Qualitativas e Quantitativas das Modalidades Sensoriais}

Segundo Tomatis (1978), os ouvidos, órgãos desprovidos de mobilidade própria, porém estrategicamente localizados nas laterais da cabeça, esta relativamente móvel, também desempenhariam um importante papel na percepção de um mundo externo. Enquanto as mãos, órgãos sensoriais da modalidade háptica, possuem o poder de interferir no mundo externo, alterando o formato, a direção e a velocidade dos estímulos proximais e mediais, os olhos, órgãos periféricos da visão, modalidade apta a captar, instantaneamente, formas, cores e movimentos distais, não dispõe de tal poder de interferência.
Tabela 2. Características temporais $\mathrm{x}$ espaciais das modalidades sensoriais.

\section{Características Temporais}

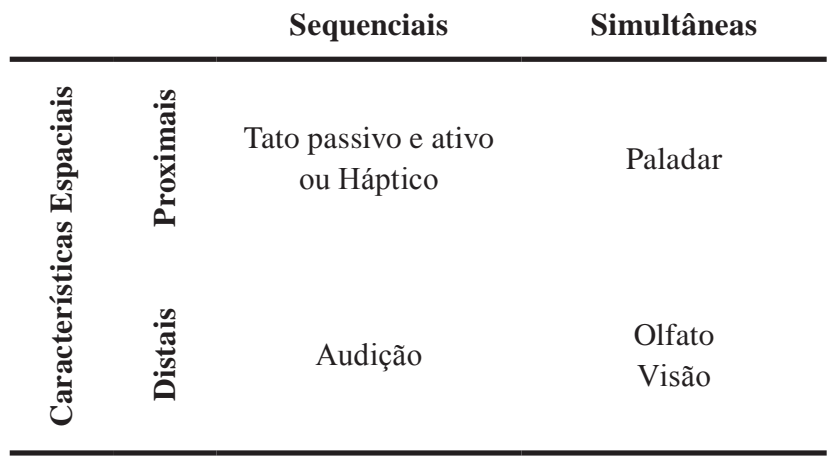

Porém, enquanto a modalidade háptica e a visual revelam, a primeira concretamente e a segunda virtualmente, a presença dos estímulos externos, a auditiva, ao relacionar esses estímulos, por meio de coordenadas espaciais, ao corpo do sujeito cognoscitivo, limita-se a insinuar presenças. Advérbios e pronomes pessoais e de lugar (eu, tu, acima, abaixo, aqui, ali, lá) evidenciam esse processo. Por outro lado, segundo Tomatis (1978), a associação que a audição estabelece com a fonação logo após o nascimento, permitindo que os recém-nascidos ouvintes se alimentem dos sons por eles mesmos produzidos, coloca a audição no rol das modalidades "autoalimentadoras precoces", isto é, aquelas cuja atividade corporal reflexa desperta a consciência volitiva. Dentre as modalidades "autoalimentadoras", a primeira a se instalar no organismo humano seria a tátil-háptica (versão mouthing), em segundo lugar a auditiva-fonatória e, finalmente, a háptica-visual (versão manual). Analisando-se a característica "autoalimentação", pode-se constatar que o prejuízo cognitivo decorrente da ausência da atividade auditiva-fonatória, causado pela surdez congênita, antecede ao prejuízo decorrente da ausência da atividade háptica-visual, causado pela cegueira congênita. A Tabela 3 relaciona de forma esquematizada a velocidade de captação dos estímulos no espaço externo das diferentes modalidades sensoriais e a mobilidade ou imobilidade de seus órgãos sensoriais periféricos.

Tabela 3. Características de mobilidade x velocidade de captação dos órgãos sensoriais periféricos.

Mobilidade

\begin{tabular}{cccc} 
& Móvel & Imóvel \\
\hline & & & \\
& & Língua, mãos (modali- & $\begin{array}{c}\text { Certas regiões da } \\
\text { pele (modalidade tátil } \\
\text { dade háptica) }\end{array}$ \\
passiva)
\end{tabular}




\section{Análise Comparativa da Influência das Características Tempo-Espaciais das Modalidades Sensoriais Faltantes e Remanescentes no Arranjo Cognitivo de Indivíduos Cegos e Surdos}

É bem conhecido o valor que as ciências humanas atribuem aos métodos que têm como finalidade avaliar o desempenho cognitivo dos homens. Neste artigo, privilegia-se um aspecto do desempenho cognitivo ainda pouco explorado, as suas características modais sensoriais "tempo-espaciais". Considerando-se as diferentes amplitudes dos campos modais sensoriais, auditivo $\left(360^{\circ}\right.$ graus $)$ e visual $\left(170^{\circ}\right.$ graus), conclui-se que, pelo menos nesse aspecto, os cegos congênitos que privilegiam a audição são mais favorecidos cognitivamente do que os surdos congênitos que privilegiam a visão. Quando se adiciona aos $360^{\circ}$ graus do "campo sensorial" auditivo os (dificilmente definíveis) X graus do "campo sensorial" da modalidade háptica e, aos $170^{\circ}$ graus do "campo sensorial" da modalidade visual os (dificilmente definíveis) X graus do "campo sensorial" da modalidade háptica, a vantagem cognitiva dos cegos persiste. Porém, quando se resolve destacar a característica "mobilidade dos órgãos sensoriais periféricos" nos arranjos cognitivos dos cegos-ouvintes e dos surdos-videntes, constata-se que, dentre as modalidades sensoriais do primeiro arranjo, só uma delas, a háptica, possui órgãos sensoriais periféricos móveis, enquanto que dentre as modalidades componentes do segundo arranjo cognitivo, duas, a hática e a visual, possuem órgãos sensoriais periféricos móveis. Além disso, quando as características, "simultânea" e "distal”, responsáveis por transformarem seres videntes em "homens de visão", é levada em conta, a anterior vantagem cognitiva atribuída aos cegos não se sustenta. Entretanto, quando a característica "fugacidade" entra em pauta, observa-se que a modalidade auditiva não dispõe do recurso "retroceder à experiência sensorial pretérita", comum às modalidades háptica e visual.

O prefixo re, presente nos verbos rever, retocar e ressentir, que denuncia o retrocesso sensorial das modalidades visual e háptica, não se aplica às funções auditivas de ouvir e escutar, ou seja, não é possível re-ouvir ou re-escutar. Essa constatação poderia sugerir que os cegos congênitos, usuários da modalidade auditiva, fossem novamente os mais prejudicados. Entretanto, se os mesmos decidem prolongar a fundamental, porém, efêmera, experiência sonora, investindo maciçamente em processos mnêmicos cognitivos representacionais como o pensamento e a imaginação, o seu arranjo cognitivo remanescente adquire um valor inesperado. Ora, como a observação de Ochaita e Rosa (1995), acerca da sobrecarga que a modalidade tátil impõe à memória de trabalho, se aplica a toda e qualquer modalidade sensorial sequencial, deduz-se que o arranjo cognitivo do cego congênito, constituído por duas modalidades sequenciais, a háptica e a auditiva, incentive o seu desenvolvimento mnêmico cognitivo representacional. Por outro lado, suspeita-se que a aparentemente vantajosa característica "retrocesso estimulatório", que dá ao surdo-vidente a possibilidade de rever, ressentir e retocar estímulos pretéritos, atue como elemento obstrutivo no seu desenvolvimento cognitivo mnêmico representacional.

O uso praticamente exclusivo, intensivo e precoce de uma modalidade "distal" e "simultânea", apta a captar instantane- amente "formas", "cores" e "movimentos", como a visual, poderia levar o surdo congênito ao confinamento cognitivo do mundo externo. Mas, então, qual seria o arranjo cognitivo remanescente mais produtivo? Aquele que, presidido pela modalidade visual, afirma e objetiva a realidade do mundo externo ou aquele que, presidido por uma modalidade que apenas insinua presenças, a auditiva, desperta dúvidas e questionamentos?

Embora muitas pesquisas tratem, separadamente, o desenvolvimento cognitivo de cegos e de surdos, poucas são as que se referem de forma explícita aos arranjos cognitivos gerados por essas diferentes privações sensoriais e menos ainda as que estabelecem análises comparativas entre esses arranjos. Por outro lado, as diferenças entre os enfoques investigatórios das pesquisas que têm como tema a falta da audição e os das pesquisas que têm como tema a falta da visão são sugestivas. Os trabalhos que visam a falta da audição enfocam, sobretudo, a problemática relacional enfrentada pelos surdos na família, na escola e no trabalho, como atestam as pesquisas de Silva e Pereira (2003) e de Oliveira, Simionato, Negrelli e Marcon (2004). Já os que visam a falta da visão enfocam a análise comparativa entre o desempenho cognitivo dos cegos e dos videntes, como os trabalhos de Laplane e Batista (2008) e de Batista (2005) comprovam. A análise das características modais sensoriais auditivas dotadas de valor "democrático" e "involuntário" e as visuais dotadas de valor "individual" e "voluntário" explicam, em parte, essas diferenças. O fato de um mesmo estímulo sonoro poder ser captado, simultânea e involuntariamente, por um grupo de cegos, enquanto que dois ou mais surdos estão impossibilitados de apreciar um mesmo estímulo a partir do mesmo ângulo de visão, embora possam vê-lo ou não, movimentando a cabeça, olhos e pálpebras, não deve ser negligenciado. Nesse sentido, ousa-se perguntar: Qual das duas modalidades interfere de forma mais positiva no processo de socialização? A audição, principal modalidade sensorial remanescente dos cegos congênitos ou a visão, principal modalidade sensorial remanescente dos surdos congênitos?

A Tabela 4 apresenta, de forma esquematizada e comparativa, as principais características dos sistemas sensoriais, auditivo e visual.

\section{Intermodalidade Sensorial e Arranjo Cognitivo}

Lécuyer (2004) oferece uma ampla revisão sobre a capacidade cognitiva de fetos, recém-nascidos e bebês. As pesquisas de DeCasper e Fifer (1980), DeCasper e Prescott (1984), Fifer e Moon (1994), Granier-Deferre, Shaal e DeCasper (2004), Schaal, Marlier e Soussignan (1998) e Schaal, Marlier e Soussignan (2000) evidenciaram que, ainda durante o período gestacional, os fetos estão aptos a memorizar não só o cheiro do liquido amniótico, da placenta e dos alimentos ingeridos pela mãe nos últimos meses de gravidez, como também que os recém-nascidos são capazes de distinguir, não só a voz materna da paterna, como também melodias e frases pronunciadas pela mãe durante a fase intra-uterina. Como nesse período do desenvolvimento as modalidades sensoriais funcionais disponíveis ao feto são o olfato, a gustação, a audição, o 
tato passivo e o háptico (sobretudo na versão mouthing), todas de baixo ou médio poder configurador, pressupõe-se que as representações por elas geradas não tenham o valor de configuração das produzidas, mais tarde, pelas modalidades dotadas de órgãos sensoriais periféricos móveis, como a visual e a háptica (versão manual).

Os conceitos de modalidade sensorial "inferior" e "superior", desenvolvidos por Proust (1997), facilitam o entendimento das alternâncias perceptivas intermodais que ocorrem durante os primeiros meses de vida do bebê humano. Proust entende como modalidade inferior uma modalidade sensorial primária, menos elaborada e complexa, de implantação precoce, apta a captar estímulos geralmente proximais, de forma sequencial e não contextualizada, e como modalidade sensorial superior, uma modalidade secundária, bem mais elaborada e complexa, de implantação tardia, apta a captar estímulos distais de forma simultânea e contextualizada. Proust justifica a alternância modal sensorial que ocorre no primeiro ano de vida do bebê da seguinte maneira: sempre que o órgão sensorial periférico de uma modalidade sensorial considerada inferior adquire mobilidade intencional e voluntária, passando a competir de igual para igual com o órgão sensorial periférico móvel de uma modalidade considerada superior, a modalidade até então considerada inferior assume as características qualitativas e quantitativas da modalidade sensorial superior. Segundo Hatwell e cols. (2000), Proust (1997) e Lécuyer (2004), o bebê vidente-ouvinte, de dois meses de idade, está apto a reconhecer visualmente estímulos previamente manipulados. Se, conforme esses autores, as modalidades consideradas de baixa ou nula capacidade de configuração como o olfato, a gustação e a audição são as principais responsáveis pelo impulso cognitivo de busca objetal que ocorre ainda in utero, deduz-se que, por ocasião do nascimento, o bebê cego-ouvinte estaria, assim como o vidente-ouvinte, apto a exercer movimentos de busca direcionada frente aos estímulos olfativos, gustativos e auditivos. Em consequência, Adelson e Fraiberg (1974) distinguem, nos primeiros meses do desenvolvimento motor do bebê cegoouvinte, duas diferentes etapas. Uma que vai do nascimento até os seis meses de idade, durante a qual praticamente não são observadas diferenças cognitivo-comportamentais entre a criança vidente-ouvinte e a cega-ouvinte, e uma outra, que se inicia aos seis meses de idade, na qual essas diferenças começam a surgir. As pesquisas de Hatwell (2003) com crianças cegas-ouvintes reforçam esses achados. Comparativamente, o bebê surdo-vidente que foi, ainda in útero, privado da estimulação auditiva responsável pelo despertar da curiosidade e do impulso cognitivo voluntário, enfrentaria outro tipo de dificuldade. Sem o anúncio antecipatório do estímulo sonoro, os estímulos visuais que adentram o campo visual do bebê surdo-vidente são desprovidos de significados prévios. Embora as modalidades, olfativa e gustativa, disponíveis ao bebê surdo-vidente também insinuem a presença de certos estímulos, elas não possuem o valor "voluntário"

Tabela 4. Modalidades sensoriais distais (visual e auditiva).

Sistema Auditivo

Campo sensorial de 350 graus.

Estímulo extremamente efêmero.

Não passível de retrocesso cognitivo.

Poder de configuração

Baixa configuração: apenas insinua a presença do estímulo.

Social

Caráter democrático e involuntário.

O estímulo sonoro se impõe aos ouvintes sem

direito de escolha. Todos os ouvintes percebem o mesmo estímulo sonoro mais ou menos da mesma forma, apenas a sua intensidade varia.

A captação auditiva permite sobreposição de estímulos.

\section{Implantação e maturação}

Volitivo
Implantação precoce (mais ou menos seis meses de idade gestacional) e maturação lenta.
Sistema Visual

Campo sensorial de 170 graus.

Estímulo duradouro.

Passível de retrocesso cognitivo.

Alta configuração: revela a presença do estímulo.

Caráter individual e voluntário.

Os videntes podem selecionar o que querem ver e

o que não querem ver (fechar as pálpebras, desviar o olhar).

O estímulo visual não se apresenta da mesma forma para dois ou mais sujeitos, pois, dependendo do ângulo de visão, a sua forma se altera.

A captação visual não pode ser sobreposta; parte ou a totalidade do estímulo desaparece na sobreposição.

Implantação tardia (no momento do nascimento a visão é ainda uma modalidade incipiente) e maturação lenta.

Sistema de auto-alimentação precoce e voluntário. Sistema de auto-alimentação tardio e voluntário. 
adquirido pela audição durante a atividade "autoalimentadora" audição-fonação.

Aos cinco meses de idade, de acordo com Hatwell e cols. (2000), Proust (1997) e Lécuyer (2004), a primitiva cronologia intermodal sensorial do bebê vidente-ouvinte se inverte fazendo com que ele perca, momentaneamente, a capacidade de reconhecer visualmente os objetos por ele anteriormente experimentado por meio do tato. Surpreendentemente, nessa ocasião, ainda segundo os mesmos pesquisadores, o bebê vidente-ouvinte torna-se apto a reconhecer, por meio da manipulação tátil, os objetos anteriormente experimentados por meio da visão. Como o bebê cego-ouvinte, ao contrário do vidente-ouvinte e do surdo-vidente, não teve a oportunidade de elaborar, na fase anterior, um acervo de memórias sensoriais visuais de forte poder configurador, propõe-se que as suas primeiras e limitadas experiências hápticas, sobretudo às referentes à versão mouthing, se associem às memórias de baixo teor de configuração, insinuadoras de presenças, olfativas, gustativas e auditivas, armazenadas ainda durante a vida intra-uterina. Dessa forma, enquanto que o bebê videnteouvinte se dedica, nessa fase, a associar uma modalidade de grande poder de configuração, como a visual, a uma outra de poder de configuração relativo, como a háptica, o bebê cego-ouvinte dedica-se a associar uma modalidade sensorial de baixo poder de configuração e alto poder insinuativo e volitivo, como a audição, a uma modalidade de poder de configuração ainda elementar nessa fase do desenvolvimento, a háptica. Já para o bebê surdo-vidente as dificuldades são outras. Não tendo tido a sua curiosidade e vontade cognitivas devidamente despertadas durante a vida intra-uterina em decorrência da falta da audição, ele entraria na segunda fase do desenvolvimento intermodal sensorial com muitas memórias visuais, porém pouco significativas. Assim, como já aconteceu com a estimulação visual, a estimulação háptica captada pelo bebê surdo-vidente no mundo externo não será precedida pelo impulso cognitivo da insinuação sonora que, no bebê ouvinte-vidente, antecede e prepara as experiências sensoriais tátil-háptica e visual, e no bebê cego-ouvinte, antecede a experiência tátil-háptica.

Finalmente, ainda de acordo com Hatwell e cols. (2000), Proust (1997) e Lécuyer (2004), por volta dos seis meses de idade cronológica, o bebê acrescenta à sua recém adquirida capacidade de reconhecer, por meio da visão, estímulos previamente avaliados por meio da modalidade háptica manual, outra capacidade inicialmente exibida quando ele tinha apenas dois meses de idade: a de reconhecer, agora também por meio do aprimorado tato ativo ou háptico manual, os estímulos anteriormente experimentados por meio da visão. Na Tabela 5 pode-se visualizar de forma resumida e esquematizada as principais características das modalidades sensoriais distais acima tratadas, a visual e a auditiva.

\section{Considerações Finais}

Tendo como base as características quantitativas e qualitativas das modalidades sensoriais tátil-háptica (versão mouthing e manual), auditiva e visual, pretendeu-se estabelecer uma análise comparativa teórica entre a eficácia do arranjo cognitivo remanescente dos cegos congênitos, cons-
Tabela 5. Resumo das principais características das modalidades sensoriais distais (visual e auditiva).

Modalidades sensoriais distais

\begin{tabular}{ll} 
Visual & Auditiva \\
\hline Fornece evidências & Fornece indícios \\
Simultânea & Sequencial \\
Espacial & Temporal \\
Concretiza & Abstrai \\
Singulariza & Generaliza \\
Sincrônica & Não sincrônica \\
Analógica & Conceitual \\
Imediata & Mediata \\
Configuradora & Não configuradora \\
\hline
\end{tabular}

tituído, principalmente, pela modalidade sensorial auditiva e pela modalidade sensorial háptica, e a eficácia do arranjo cognitivo remanescente dos surdos congênitos, constituído, principalmente, pela modalidade sensorial visual e pela modalidade sensorial háptica. Embora este trabalho teórico possa gerar mais questões e dúvidas do que afirmações e certezas, algumas diretrizes podem ser esboçadas: (1) o conhecimento das razões que regem a cronologia das características modais sensoriais, "implantação" e "maturação", nos sujeitos videntes-ouvintes, é essencial para que sejam entendidas algumas das diferenças cognitivo-comportamentais dos indivíduos sensorialmente privados; (2) a mobilidade dos órgãos sensoriais periféricos é fundamental na configuração dos estímulos e na construção de um espaço distal externo; (3) a avaliação dos arranjos cognitivos pressupõe a análise das características quantitativas e qualitativas modais sensoriais constituintes e das relações de dominância que elas estabelecem entre si; (4) o uso exclusivo da modalidade sensorial visual, na ausência da modalidade sensorial auditiva que ontologicamente a antecede, aparentemente, gera mais prejuízos do que benefícios ao desenvolvimento cognitivo mnêmico representacional do indivíduo surdo-vidente; (5) o uso conjunto da modalidade sensorial auditiva e da modalidade háptica, na ausência da modalidade sensorial visual que ontologicamente a sucede, aparentemente, estimula o desenvolvimento cognitivo mnêmico representacional do indivíduo cego-ouvinte.

\section{Referências}

Adelson, E., \& Fraiberg, S. (1974). Gross motor development in infants blind from birth. Child Development, 45,114-126. 
Adrien, J. (1977). Le sommeil du nouveau-né. Em J. Adrien \& M. Blanc (Orgs.), La Recherche en Neurobiologie (pp. 165-170). Paris: Editions Du Seuil.

Bach-y- Rita, P. (1972). Brain mechanisms in sensory substitution. New York: Academic Press.

Bach-y-Rita. P., \& Sampaio. E. (1995). Substitution sensorielle chez les adultes et les enfants aveugles. Em Y. Christen, M. Doly \& M. T. Droy-le-Faix (Eds.), Vision et adaptation (pp. 108-116). Paris: Elsevier.

Batista, C. G. (2005). Formação de conceitos em crianças cegas: questões teóricas e implicações educacionais. Psicologia: Teoria e Pesquisa, 21, 7-15.

DeCasper, A. J., \& Fifer W. P. (1980). Of human bonding: Newborns prefer their mother's voice. Science, 208, 1174-1176.

DeCasper, A. J., \& Prescott P. A. (1984). Human newborn's perception of male voices, preference, discrimination, and reinforcing value. Developmental Psychobiology, 17, 481- 491.

Fifer, W. P., \& Moon, C. M. (1994). The role of mother's voice in the organization of brain function in the newborn, Acta Paediatrica, 397, 86-93.

Granier-Deferre, C., Shaal, B., \& DeCasper A. J. (2004). Les premices foetales de la cognition. Em R. Lécuyer (Org.), Le development du nourrisson (pp. 101-128). Paris: Dunod.

Gibson, E. J., \& Walker, A. S. (1984). Development of knowledge of visual-tactual affordances of substance. Child Development, 55, 453-460.

Gottfried, A. W., Rose, S. A., \& Bridger, W. E. (1977). Crossmodal transfer in human infants. Child Development, 48, 118123.

Hatwell, Y. (2003). Psychologie cognitive de la cécité precoce. Paris: Dunod.

Hatwell, Y., Streri, A., \& Gentaz, E. (2000). Toucher pour connaître. Psychologie cognitive de la perception tactile manuelle. Paris: PUF.

Imbiriba, L. A., Oliveira, L. A., Russo, M. M., Fontana, A. P., Rodrigues, E. C., Magalhães, J., \& Vargas, C. D. (2008). Movementrelated cortical potencials in blind and sighted ubjects. Clinical Neurophysiology, 119, e131.

Imbiriba, L. A., Rodrigues, E. C., Magalhães, J., \& Vargas, C. D. (2006). Motor imagery in blind subjects: The influence of the previus visual experience. Neuroscience Letters, 400, 181-185.

Joffily, S. B. (1995). O sonho precursor da individualidade nos mecanismos sociais humanos. Revista de Psicologia Clínica, 7, 59-84

Joffily, S. B. (2004). Sono paradoxal e espaço externo. Em R. Reimão (Org.), Sono: sono normal e doenças do sono (pp. 231-234). São Paulo: Associação Paulista de Medicina.

Jouvet, M. (1998). Paradoxal sleep as a programming system. Journal Sleep Research, 7, 1-5.

Kastrup, V. (2007). A invenção na ponta dos dedos: a reversão da atenção em pessoas com deficiência visual. Psicologia em Revista, 13, 69-90.
Laplane, A. L. F., \& Batista, C. G. (2008). Ver, não ver e aprender: a participação de crianças com baixa visão e cegueira na escola. Cadernos Cedes, 28, 209-227.

Lécuyer, R. (2004). Le développement du nourrisson. Paris: Dunod.

Meltzoff, A. N., \& Borton, R. W. (1979). Intermodal matching by human neonates. Nature, 282, 403-404.

Ochaita, E., \& Rosa, A. (1995). Percepção, ação e conhecimento nas crianças cegas. Em C. Coll, J. Palácios \& A. Marchesi (Orgs.), Desenvolvimento psicológico e educação (pp.183-197). Porto Alegre: Artes Médicas.

Oliveira, R. G., Simionato, M. A. W., Negrelli, M. E. D., \& Marcon, S. S. (2004). A experiência de famílias no convívio com a criança surda. Acta Scientiarum. Health Sciences, 26, 183-191.

Pêcheux, M.G., Lepecq J. C., \& Salzarulo P. (1988). Oral activity and exploration in 1-2 month-old infants. British Journal of developmental Psychology, 6, 245-256.

Proust, J. (1997). Perception et intermodalité. Approches actuelles de la question de Molyneux. Paris: PUF.

Radeau, M. (1997). Du ventrilogue à l'embryon: Une réponse à Molyneux. Em J. Proust (Org.), Perception et intermodalité. Approches actuelles de la question de Molyneux (pp. 223-252). Paris: PUF.

Rochat, P. (1983). Oral touch in young infants: Response to variations of nipple characteristics in the first months of life. International Journal of Behavioral Development, 6, 123-133

Ruff, H. A., Saltarelli, L. M., Capozzoli, M., \& Dubiner, K. (1992). The differentiation of activity in infants exploration of objects. Developmental Psychology, 28, 851-861.

Schaal, B., Marlier L., \& Soussignan R. (1998). Olfactory function in the human fetus, evidence from selective neonatal responsiveness to the odour of amniotic fluid, Behavioral Neuroscience, 112, 1438-1449.

Schaal, B. Marlier L., \& Soussignan R. (2000). Human fetuses learn odours from their pregnant mother's diet. Chemical Senses, 25, 729-737.

Segond, H., Weiss, D., \& Sampaio, E (2007). Can we propose a tactile vision substitution system to blind babies? Journal of Visual Impairment and Blindness, 101, 32-43.

Silva, A. B. P., \& Pereira, M. C. C. (2003). O aluno surdo na escola regular: imagem e ação do professor. Psicologia: Teoria e Pesquisa, 19, 173-176.

Tomatis, A. (1978). L'oreille et le language. Paris: Éditions du Seuil.

Recebido em 14.05.08 Primeira decisão editorial em 29.01.09 Versão final em 23.03 .09 Aceito em 02.04.09 